\title{
Work in Process: Collaborative Design Projects
}

\section{Dr. Mohammad Habibi P.E., University of Wisconsin, Platteville}

Mohammad Habibi is an Assistant Professor in the Department of Electrical and Computer Engineering at the University of Wisconsin-Platteville. Prior to coming to the UW-Platteville, he was an assistant professor of Integrated Engineering at Minnesota State University-Mankato. He earned his Ph.D. degree in Electrical Engineering from the University of Wisconsin-Milwaukee in 2010. His primary research interests are in the field of signal processing, dielectric spectroscopy, and sensors. Specifically, he is interested in developing novel medical devices. In addition to his technical research, he is also an active member of the American Society of Engineering Education (ASEE) and conducts research in engineering education.

\section{Dr. Lily Chang, University of Wisconsin, Platteville}

Dr. Chang earned her PhD in Computer Science from Florida International University and her Master of Science in Computer Science from New Jersey Institute of Technology. Her primary research area involves software engineering, specifically formal specification.

Dr. Chang is an associate professor and the program coordinator of the software engineering program at the University of Wisconsin - Platteville. She is a member of the American Society for Engineering Education and Association for Computing Machinery. 
Work in Process: Collaborative Design Projects 


\begin{abstract}
Soft skills such as leadership, effective communication and being able to function in multidisciplinary teams are required to be successful in engineering workplaces. The complexity of engineering problems has required engineers to work effectively in multidisciplinary teams. Therefore, multidisciplinary capstone design has been becoming a regular practice in engineering schools. However, collaborative design among multiple disciplines for non-capstone courses has been neglected. In spring 2018, students enrolled in Measurements and Instrumentation (an Electrical Engineering course) and Software Maintenance and Reengineering from Computer Sciences and Software Engineering department collaborated on five Internet of Things (IoT) projects. The collaboration has revealed both challenges and positive outcomes. This paper describes the collaboration, the students' feedback and lessons learned.
\end{abstract}

\title{
1. Introduction
}

Engineering projects have become complex in the $20^{\text {th }}$ century and require multiple teams from different disciplines to work collaboratively to solve problems. Collaboration between multidisciplinary teams has become a standard in industries; however, educational curricula have been slow to adapt. Although most engineering programs have a capstone design course as a part of their curricula and students work together in a team setting, collaborating with other disciplines has been neglected.

The ability to collaboratively function in multidisciplinary teams has been an active research area in engineering education. The ability to work successfully in multidisciplinary teams and the ability to design products or systems are two essential skills that every engineering student must have before graduation [1,2]. Furthermore, today's technology requires a multidisciplinary approach to meeting economic, social, and environmental requirements. The Accreditation Board for Engineering and Technology (ABET) has been promoting multidisciplinary teamwork because of the exponential growth of knowledge and technology, that has made multidisciplinary teamwork a necessity in engineering [3]. The new ABET Criterion 3, approved for 2019-2020 cycle, and has revised its teamwork related outcome to include leadership and collaboration [4].

Fortunately, multidisciplinary teamwork is becoming a common practice in capstone design courses. For example, electrical and mechanical engineering $[5,1]$, biomedical and mechanical engineering [6], and civil and electrical engineering students [7] have worked together in capstone design courses. These capstone courses encourage students to be familiar with concepts in other disciplines and provide opportunities to practice their skills. Working with other disciplines without being aware of their concepts has been reported to be a major challenge for both students and faculty $[8,9]$. However, it has been reported that multidisciplinary teamwork would improve the performance of students. A quantitative analysis of the effects of a multidisciplinary engineering design course has been published [10]. This study shows that students participated in a multidisciplinary teamwork had better performance in innovation, utility, analysis, proof of concept, and communication skills to that of their monodisciplinary counterparts. Furthermore, the collaboration between geographically distributed, multidisciplinary teams has been published by 
William O'Brien and Lucio Soibelman [11]. They developed a collaborative capstone design course where graduate students from the University of Illinois at Urbana-Champaign and the University of Florida collaboratively work together. Although multidisciplinary capstone design has been reported [12-18], collaborative work between two non-capstone design courses from two departments is not a common practice.

During the spring of 2018, students from Measurement \& Instrumentation course, an intensive design course from the department of electrical engineering, and Software Maintenance and Reengineering (a project-driven course from the department of computer science and software engineering) worked collaboratively on five IoT projects. The electrical engineering students designed, and tested hardware, and the computer science and software engineering students created and implemented cloud-based web servers and frontend user graphical interfaces.

This paper describes the objectives, outcomes and significance of this collaboration. Students from both departments described the collaboration as a unique learning opportunity that provided both challenges and success. A survey was conducted to collect students' opinions from both classes. In addition to lessons learned, the results of the survey will be discussed in this paper.

\section{Course description}

Measurements and Instrumentation: Measurement and Instrumentation (M\&I) is offered in many engineering and technology schools to introduce undergraduate engineering students to the measurement principles and instruments used for measuring physical quantities [19].

Table 1. The content and learning objectives of Measurements and Instrumentation course offered at the University of WisconsinPlatteville

\begin{tabular}{|c|c|}
\hline Content & Learning objectives \\
\hline $\begin{array}{ll}> & \begin{array}{l}\text { Measurement systems } \\
\text { and instrument } \\
\text { characteristics. }\end{array} \\
> & \text { Error analysis. } \\
> & \text { Noise and interference } \\
& \text { in instrumentation. } \\
> & \text { Signal conditioning. } \\
> & \text { Internet of Things (IoT). } \\
> & \text { Sensor applications. } \\
> & \text { Data acquisition, digital } \\
\text { interfaces (A/D and } & \text { D/A). } \\
> & \text { Discussion of specific } \\
\text { sensor systems. }\end{array}$ & $\begin{array}{l}\text { Understand the fundamental principles of measurement } \\
\text { and uncertainty. } \\
>\text { Ability to analyze measurement systems. } \\
\text { Ability to design, calibrate, and characterize a } \\
\text { measurement system to measure mechanical or electrical } \\
\text { variables. } \\
>\text { Understand the fundamental of IoT and be able to design } \\
\text { and implement an IoT system } \\
>\text { Gain an understanding of some of the specific sensor } \\
\text { systems. } \\
>\text { Ability to use Lab VIEW in implementing a modern } \\
\text { measurement system. } \\
>\text { Understand modern sensor systems for measuring a variety } \\
\text { of physical quantities. } \\
>\text { Ability to work in a multidisciplinary team }\end{array}$ \\
\hline
\end{tabular}


In recent years, advanced topics such as smart sensors, intelligent instruments, IoT, and digital components (eg. storage, displays, interfaces, etc.) have been added to the content of the course. Applications of this course include but are not limited to building automation, industrial control systems, and safety controls. The M\&I course was developed in 2017 and has been taught every spring since then at the University of Wisconsin-Platteville. The course compromises of three hours of lectures and two hours of lab weekly. For the hands-on portion of the course, students are required to do three mini and one final projects. The final project must be a multi-sensors/actuators product with IoT capabilities. In the final project, the students work in a team setting with three to five members. Course objectives and contents can be seen in Table 1.

The course assessment consists of exams (50\%), projects (30\%), weekly quizzes (10\%) and a survey paper $(10 \%)$. Out of $30 \%$ of project grades, $10 \%$ was dedicated to the final project and another $20 \%$ to 3 mini individual projects. The detail of course assessment is shown in Table 2 .

Table 2. M\&I course assessment

\begin{tabular}{|l|l|}
\hline Course components & Percentage \\
\hline Exams (Exam I ,II ,III) & $50 \%$ \\
\hline Projects (4 Projects) & $30 \%$ \\
\hline Quiz (10 weekly quiz) & $10 \%$ \\
\hline Survey paper & $10 \%$ \\
\hline
\end{tabular}

Software Maintenance and Reengineering: Computer Science and Software Engineering (CSSE) graduates often start their first job in maintaining existing systems. However, courses focusing specifically on software maintenance and reengineering are rare among the undergraduate programs in the field. The Software Maintenance and Reengineering course offered by the department of computer science and software engineering covers the topics related to maintaining large-scale software systems, the traditional analysis and design methods. Other topics, such as software evolution, IEEE maintenance process model and maintenance activities, legacy systems, reverse engineering, refactoring, and regression testing, are also covered. Students gain experience via semester-long, team-based projects in developing, maintaining, or reengineering software systems. The course outcomes include:

- Understand the role of maintenance in software development.

- Understand the ISO/IEC 12207 Software Life-cycle Processes w.r.t software evolution.

- Perform a structured analysis and design small project.

- Plan, analyze, design, implement, and test modifications to an existing software project.

- Understand the issues of a software system port.

- Understand the issues of software reengineering.

- Understand the issues related to outsourcing software projects.

- Work effectively in a team on a software maintenance or reengineering project.

- Become familiar with reverse engineering strategies. 
This course is required and taken by the CSSE majors in their junior or senior years. Software engineering students take this course in their junior or senior year. This course provides a major design experience through the software projects. Students typically work on a software maintenance project and a reengineering project in a group of four to five within a semester. We are particularly interested in working on the software projects involving new technology, new tools, and platforms; for example, cloud-based applications. As a consequence, students gain handon experiences in functional and architectural transformation in the area of software reengineering. The maintenance and reengineering projects contribute $44 \%$ toward their final grade. The students work on a maintenance project for the first half of the semester, and work on a reengineering project for the second half of the semester. Both projects have weekly review presentations to keep the students on track.

\section{Collaboration description and objectives}

The interdisciplinary collaboration has been encouraged in the University of WisconsinPlatteville. In spring 2018, two faculty members from the department of Electrical Engineering (EE) and department of CSSE had structured collaboration between two non-capstone design courses: M\&I and Software Maintenance and Reengineering. In this collaboration, students from both departments worked on the same final project where EE students designed the hardware section and CSSE students added the IoT capabilities by designing the webserver and frontend user graphical interface. The main goal for the collaboration was to provide professional development opportunities for students from both disciplines. The objectives of this collaboration were:

1. To be able to share knowledge and explain project specification to other disciplines and also to be introduced to concepts in different disciplines.

2. To be able to function in a multidisciplinary team.

3. To do their best work and be able to apply their skills within real-world settings.

\section{Final project}

A final project menu was developed at the beginning of the semester by the EE students, faculty and local industry. The EE students were given a chance to choose the project that they were most interested in. Each EE student was responsible for developing a sensor-based circuit to measure a related physical quantity. After the EE teams were formed, a final project kickoff day event was scheduled in the $5^{\text {th }}$ week of the semester to invite the CSSE students and to introduce the projects. Each EE team introduced themselves and presented their project in some details. They also described how the CSSE students could help them to complete their project. Then, each four or five CSSE students selected an EE team to work with. They also exchanged contact information and decided how they wanted to get in touch. 


\begin{tabular}{|c|c|}
\hline Project & Description \\
\hline $\begin{array}{l}\text { Power line } \\
\text { monitoring }\end{array}$ & $\begin{array}{l}\text { A power line monitoring system was designed to monitor current, temperature, inclination and } \\
\text { tension of power lines. The system consists of four sensors: current, temperature, inclination, and } \\
\text { tension. Four sensors were chosen and signals were conditioned to output } 0 \mathrm{~V} \text { when the line is in } \\
\text { normal condition and } 1 \mathrm{~V} \text { when fault happens. Each sensor works simultaneously with one another. } \\
\text { The analog reading from the circuits is read by the ESP } 8266 \text { chip, which then transfers the data to } \\
\text { the web server. The SE students designed the web server and the graphical user interface where the } \\
\text { data can be read remotely by the user. }\end{array}$ \\
\hline $\begin{array}{l}\text { Transformer } \\
\text { monitoring }\end{array}$ & $\begin{array}{l}\text { The quality, level, and temperature of transformer oil are important quantities to monitor for both } \\
\text { safety and operational purposes. Currently, technicians need to manually check these quantities, and } \\
\text { even send oil samples to a laboratory. This project aimed at utilizing an Internet of Things (IoT)- } \\
\text { based platform to measure these quantities remotely. In this system, oil temperature, oil level and oil } \\
\text { permittivity are measured with custom transducers. This information is then collected and sent to a } \\
\text { remote server that can be accessed from any computer or smart phone. This real-time information } \\
\text { could reveal problems within a transformer or elsewhere in the power system, creating a more } \\
\text { precise way to dispatch system maintenance. SE students designed and implemented a webserver } \\
\text { and graphical interface, so the data can be monitored remotely also the user is able to take the } \\
\text { transformer off the grids remotely. }\end{array}$ \\
\hline $\begin{array}{l}\text { Smart } \\
\text { Parking } \\
\text { Management }\end{array}$ & $\begin{array}{l}\text { The purpose of this project was to determine the vacancy of parking spaces in any parking lot using } \\
\text { advanced image processing techniques. These techniques were implemented using Raspberry Pi } 3 \\
\text { with the Raspberry Pi Camera Module V2. The accuracy for this project should be a minimum of } 80 \\
\text { percent on a sunny day from 8:00 am to 4:00 pm. We used the parking lot behind Engineering Hall, } \\
\text { which contains } 83 \text { spots. A server backend and a graphical user interface were implemented by } \\
\text { software engineers and served via web application. }\end{array}$ \\
\hline Smart Burn & $\begin{array}{l}\text { The objective of this project was to create a system that monitors the wellbeing of hogs on a hog } \\
\text { farm. The project incorporates humidity, temperature, methane and weight sensors. The humidity, } \\
\text { temperature, and methane sensors are responsible for maintaining a safe and healthy environment } \\
\text { for the hogs, while the weight sensor was used to monitor the amount of feed in the feed bin to } \\
\text { ensure more feed is ordered before it runs out. All these things can be monitored by owners } \\
\text { checking gauges occasionally, but the goal was to make the system automated. Additionally, the } \\
\text { system controls the fans and heater; when the humidity, temperature or methane is above the high } \\
\text { threshold, a fan will be activated to bring the levels of everything back down. If the low temperature } \\
\text { threshold is reached, then a heater will activate to bring it back up. Moreover, a texting system was } \\
\text { design so the manager will also be sent a message informing the action that was carried out to } \\
\text { stabilize the environment. A server backend and a graphical user interface were implemented by SE } \\
\text { students to monitor and control the burn remotely via web application. }\end{array}$ \\
\hline $\begin{array}{l}\text { Smart } \\
\text { Hydroponic } \\
\text { systems }\end{array}$ & $\begin{array}{l}\text { Hydroponic systems traditionally require an extreme amount of maintenance to produce a successful } \\
\text { yield. The objective of this project was to automate the process of hydroponics. We implemented } 5 \\
\text { sensors to monitor and automate the process of hydroponics. The parameters our system tracks were } \\
\text { soil moisture, light intensity, electrical conductivity of nutrient the solution (to determine level of } \\
\text { nutrients), temperature of the nutrient solution, and temperature of the air. A system prototype has } \\
\text { been designed which implements the five sensors listed above in conjunction with a cloud hosted } \\
\text { data server, designed by a team of SE students, which allows the user to interface with the sensor } \\
\text { data in real time. The prototype provided remote access to real time sensor data, automatically } \\
\text { actuate control signals to control a water pump or led lights, as well as sending the user notifications } \\
\text { when pertinent factors of the systems exceed or fall behind predetermined levels. }\end{array}$ \\
\hline
\end{tabular}


Additionally, an IoT demo project was demonstrated consisting of a temperature sensing circuit, cloud-based webserver, and a frontend graphical user interface. The demo helped both EE and CSSE students visualize of how they want to design and build their projects. Also, some of the objectives of collaboration were explained. The students from both departments agreed that the EE student are responsible for developing the hardware portion of the project and CSSE students are in charge of implementing the webserver, and frontend graphical user interface. There were total of five projects, $18 \mathrm{EE}$ and $24 \mathrm{CSSE}$ students were involved with this collaboration. The total of five teams were formed consisting of five to eight students from both departments. A list of final projects and their description is shown in Table 3.

\section{Assessment}

The collaboration project was worth 100 points, which was a total of $10 \%$ of the final grade for EE students. The grade for the project was consisted of individual work (30\%), and teamwork (70\%). The EE students were required to write a formal report describing their design in detail, give an oral presentation and show a demo of their functioning prototype. The teamwork grade was based on presenting a functioning product, and teamwork with both the EE and the CSSE teammates. One team failed the collaboration by not implementing CSSE work and lost a large portion of their teamwork grade. The rest of the teams did a good job on their teamwork with both EE and CSSE teammates.

The CSSE students utilized the second half of the semester working with EE students on the IoT projects. This project was worth a total of 130 points, which was $26 \%$ of their final grade. There were six major deliverables. The CSSE students were required to present and demonstrate their work every Friday. Each deliverable had a list of requirements announced two weeks before it was due. The deliverables were graded as a team based on how well the team was meeting the requirements. The grading components for each deliverable included the documentation, presentation, an individual reflection paragraph and the source code. Since the CSSE students had weekly reviews, they were able to keep up with the schedule and meet the requirements. All the CSSE teams completed the web servers utilizing AWS or Microsoft Azure, and completed the graphical user interface for visualizing the sensor data.

\section{Reflective Critiques}

Prior to the end of the course, an anonymous survey was administered to students to gauge their opinions about the collaboration. The survey was developed in-house and compromised of 12 questions. The questions were mainly multiple-choice, but also included a comment box. The questions of the survey can be seen in Table 4. Thirteen EE and fourteen CSSE students completed the survey. The results of questions 7, 10,11 and 12 are shown in Figure 1. The results of the rest of the questions can be found in the appendix section.

The CSSE students developed a plan at the beginning of collaboration, but EE students developed theirs half-way through the collaboration. This might be because projects specifications were determined by the EE students and these specifications might have changed in the middle of 


\begin{tabular}{|c|c|c|}
\hline & Questions & Possible answers \\
\hline 1 & What type of communication method did you use? & $\begin{array}{l}\text { Face-to-face, email, text messaging, video } \\
\text { chat }\end{array}$ \\
\hline 2 & How often did you meet? & $\begin{array}{l}\text { Never meet in person, once, a couple of } \\
\text { times, } 3 \text { times, } 4 \text { times, five and more }\end{array}$ \\
\hline 3 & Did your team have a communication representative spokesman)? & Yes,no, others \\
\hline 4 & Were your team timeline and SE team timeline synced? & Yes,no, others \\
\hline 5 & $\begin{array}{l}\text { Are you satisfied or dissatisfied with the overall quality of the work } \\
\text { performed by SE team? }\end{array}$ & $\begin{array}{l}\text { Very satisfied, satisfied, neutral, } \\
\text { dissatisfied, very dissatisfied, other }\end{array}$ \\
\hline 6 & How did you develop the plan with SE team? & $\begin{array}{l}\text { Developed at the beginning, halfway } \\
\text { through, end, others }\end{array}$ \\
\hline 7 & Were all the specifications of the project met? & Yes, no, others \\
\hline 8 & $\begin{array}{l}\text { Did your professor give you enough guidelines to succeed the } \\
\text { collaboration? }\end{array}$ & Yes, no, partially \\
\hline 9 & $\begin{array}{l}\text { Do you think that exchanging multiple progress reports between your } \\
\text { team and the SE team will improve the quality of collaboration? }\end{array}$ & Yes, no, maybe, other \\
\hline 10 & Did working with other department motivate you to do the best work? & Yes, No, partially \\
\hline 11 & $\begin{array}{l}\text { Do you think the collaboration has a positive impact on your professional } \\
\text { development? }\end{array}$ & Yes, no \\
\hline 12 & $\begin{array}{l}\text { Overall, how would you rate the quality of the experience with the } \\
\text { multidisciplinary team? }\end{array}$ & $\begin{array}{l}\text { Very positive, somewhat positive, neutral, } \\
\text { somewhat negative, very negative }\end{array}$ \\
\hline
\end{tabular}

\section{Were all the specifications of the project met?}

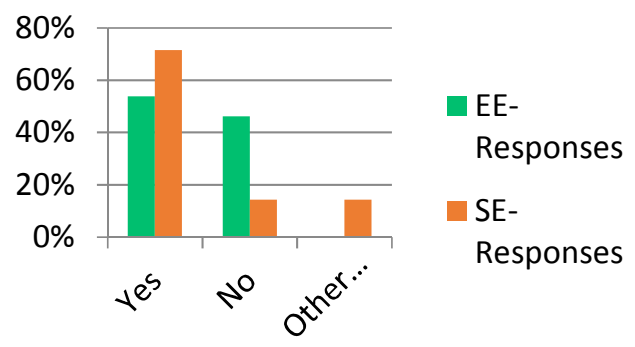

11. Do you think the collaboration has a positive impact on your professional development?

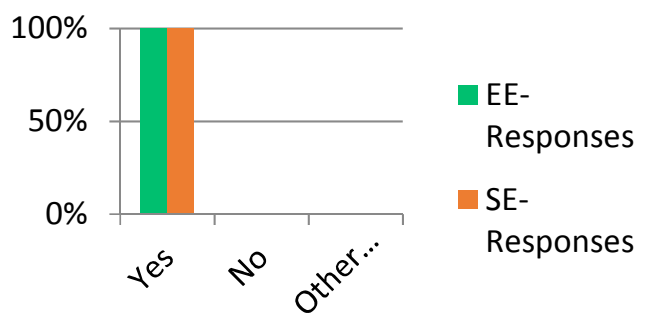

10. Did working with other department motivate you to do the best work?

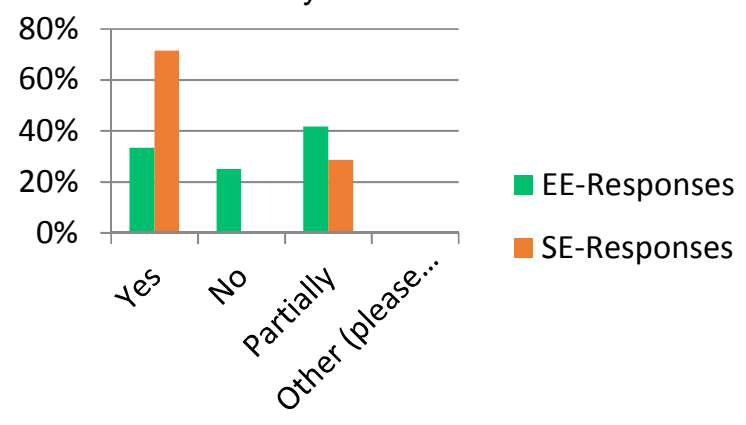

12. Overall, how would you rate the quality of the experience with the multidisciplinary team?

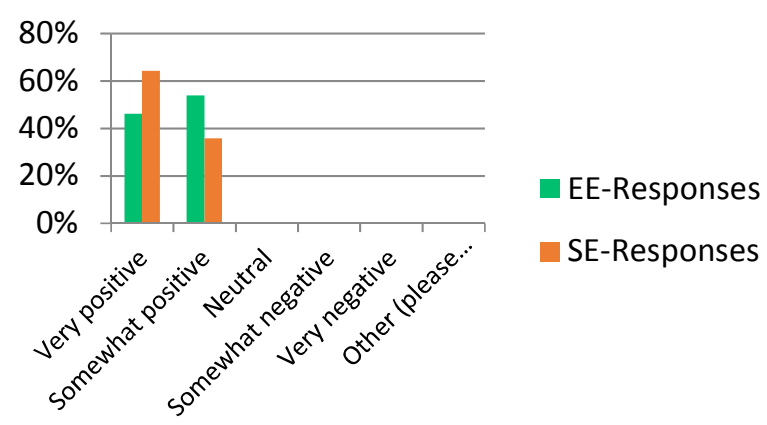

Figure 1. The results of selected survey questions 
collaboration. Both CSSE and EE students indicated that they usually used face-to-face methods to communicate, and occasionally email or text messaging. Each team met on average four times per semester to report their progress and exchange ideas. In this regard, students were self-directed and required minimum supervision or direction from the faculty.

Each EE team chose a communication representative to ease the scheduling and to reduce meeting time, where the CSSE students prefer to be communicated as a whole group. While each EE student was responsible for specific task/hardware to develop, the CSSE students work on the problem as a whole. The majority of CSSE students thought they had a synced timeline, where the responses from the EE students were mixed. As indicated in figure 1, the students from each department were satisfied with the overall quality of the work performed by the students from another department.

The majority of CSSE students thought the specifications of their project were met, but the responses from EE students were diverged; $45 \%$ thought that the specifications of the project were partially met. The majority of students from both departments thought that exchanging multiple progress reports between both EE and CSSE teams will improve the quality of collaboration and keep both timelines synced.

\section{Challenges}

Time management: time management was reported as the main challenge. The students had difficulty finding meeting times. There were five to eight students on each team, so it was a challenge to schedule a meeting that worked for everyone. However, the EE students were advised to have one representative per team to meet with CSSE students; this made the scheduling easier for them. Additionally, it appeared that both EE and CSSE students did not have a synced deadline which was frustrating for students.

Technical communication: It is always a challenge to share the concept of one discipline to another. The CSSE students had difficulties explaining the detail of their codes to EE students, and similarly, communicating specifications and limitation of the hardware to the CSSE team was difficult for EE students. In addition to communicating the full scope, neither teams were sure of what the other team members were capable of or what their limitations were. Also, there was not a good communication method for chatting or sharing files between the groups. For example, some CSSE teams used Apache Subversion (SVN) as a repository for their files, while there was no common method of file repository among the EE teams.

Learning curve: Learning new technologies in a short timeframe has a very large learning curve. SE students had to learn IoT services from multiple platforms such as Amazon AWS and Microsoft Azure in a relatively short time. Additionally, SE students did not have access to the hardware developed by their EE teammates to test their solution at any time. The EE students did not press any concern about learning new technology because they had time at the beginning of the semester to learn and test the IoT services. 
Clear expectation: Based on students' feedback, there were not clearly defined expectations by the faculty. Both CSSE and EE students thought that a more detailed plan is necessary to define the roles and responsibilities of each discipline. One student commented, "A little bit more communication between the professors is necessary, about what is allowed and not allowed for the project." Or another comment was "The two professors involved should definitely agree on expectations of the students."

\section{Future work}

Overall, the collaboration turned out to be a good experience for both students and faculty. The collaboration was started without much detailed planning because it was our first try. We will continue the work in the spring of 2019. A few changes are necessary to make this a better experience for both SE and EE students. One of the changes is to involve SE students in the process of project development. As mentioned in section 3, the project menu was originally developed by the EE students, the EE instructor, and local industry. In spring 2019, the project menu will be created using SE students' ideas as well as EE students.

To improve the communication between CSSE and EE teams, we will ask them to prepare a plan at the beginning and to define roles and responsibilities with the presence of both SE and EE faculty. One or two progress reports from one discipline to another is necessary to keep both teams on track.

\section{References}

[1] T. D. and J. D. Will. "An innovative multidisciplinary capstone design course sequence." age 8 (2003): 1.

[2] D. S. Strong "Toward effective multidisciplinary engineering education: the multidisciplinary design stream at Queen's University." Proceedings of the Canadian Engineering Education Association, CEEA 2005.

[3] ABET. 2016-2017. Criteria for Accrediting Engineering Programs. Engineering Accreditation Commission, Accreditation Board for Engineering and Technology, Baltimore, MD. [Online] Worldwide web address: https://www.abet.org/accreditation/accreditationcriteria/criteria-for-accrediting-engineering-programs-2016-2017/

[4] ABET. 2019-2020. Criteria for Accrediting Engineering Programs. Changes in Criterion 3 Student Outcomes. [Online] Worldwide web address: https://www.abet.org/wpcontent/uploads/2018/03/C3 C5 mapping SEC 1-13-2018.pdf

[4] L. Thigpen et al. "A model for teaching multidisciplinary capstone design in mechanical engineering." Frontiers in Education, 2004. FIE 2004. 34th Annual. IEEE, 2004.

[5] N. Hotaling et al. "A quantitative analysis of the effects of a multidisciplinary engineering capstone design course." Journal of Engineering Education 101.4 (2012): 630-656. 
[6] G. Hunt "A Case Study of Interdisciplinary Capstone Engineering Design.” Proceedings of the 2018 American Society of Engineering Education Annual Conference \& Exposition. 2018.

[7 ] D. M. Richter and M. C. Paretti. "Identifying barriers to and outcomes of interdisciplinary in the engineering classroom." European Journal of Engineering Education 34.1 (2009): 29-45.

[8] K. Behdinan, R. Pop-Iliev, and J. Foster. "What constitute a multidisciplinary capstone design course? Best practices, successes and challenges." Proceedings of the Canadian Engineering Education Association, CEEA 2014.

[9] Hotaling, Nathan, et al. "A quantitative analysis of the effects of a multidisciplinary engineering capstone design course." Journal of Engineering Education 101.4 (2012): 630-656.

[10] W. O'Brien, L. Soibelman and G. Elvin. "Collaborative design processes: an active-and reflective-learning course in multidisciplinary collaboration." Journal of Construction Education 8.2 (2003): 78-93.

[11] J. W., Su et al. "Lessons Learned from Multidisciplinary Senior Capstone Design Projects." Proceedings of the 2016 American Society of Engineering Education Annual Conference \& Exposition. 2016.

[12] J. Macklin and K.G. King, "Twenty Years of Multidisciplinary Capstone Projects: Design, Implementation, and Assessment," Proceedings of the 2015 American Society of Engineering Education Annual Conference \& Exposition. 2015.

[13] R.O. Hovsapian, S. Chiang, J. Ordonez, J. Vargas and N. G. Costa, 2012, "Enhancing Senior Capstone Design Course through International and Multidisciplinary Projects," Proceedings of the 2012 American Society of Engineering Education Annual Conference \& Exposition. 2012.

[14] D. Tougaw and J. D. Will, “An Innovative Multidisciplinary Capstone Design Course Sequence," Proceedings of the 2003 American Society of Engineering Education Annual Conference \& Exposition. 2003.

[15] J. Lumpp, J. Jacob, S. Smith and W. Smith, "BIG BLUE: A Multidisciplinary Capstone Engineering Design Project," Proceedings of the 2006 American Society of Engineering Education Annual Conference \& Exposition. 2006.

[16] L. Thigpen et al. "A model for teaching multidisciplinary capstone design in mechanical engineering." Frontiers in Education, 2004. FIE 2004. 34th Annual. IEEE, 2004.

[17] R. Bannerot, R. Kastor, and P. Ruchhoeft. "Multidisciplinary capstone design at the University of Houston." Advances in Engineering Education 2.1 (2010): n1.

[18] A. D. Helfrick and William David Cooper. Modern electronic instrumentation and measurement techniques. NJ.: Prentice Hall, 1990. 


\section{Appendix}

Did your professor give you enough guidelines to succeed the collaboration?

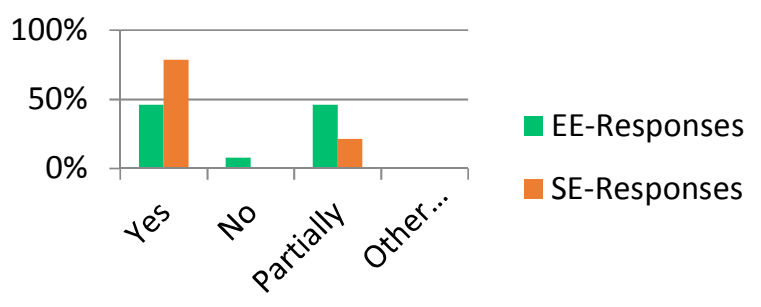

What type of communication method did you use?

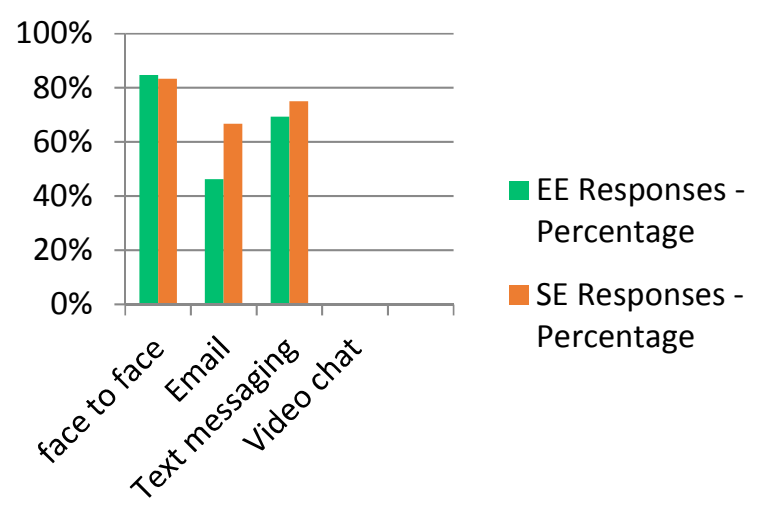

Did your team have a communication representative (spokesman)?

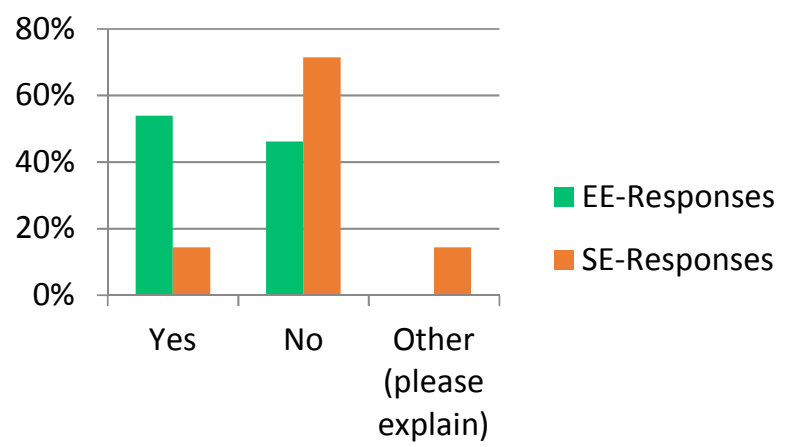

Figure 2. Results of survey questions (see table 1)
Do you think that exchanging multiple progress reports between your team and the SE team will improve the quality of collaboration?

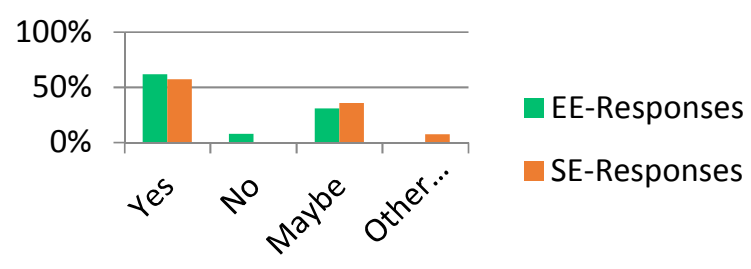

How often did you meet?

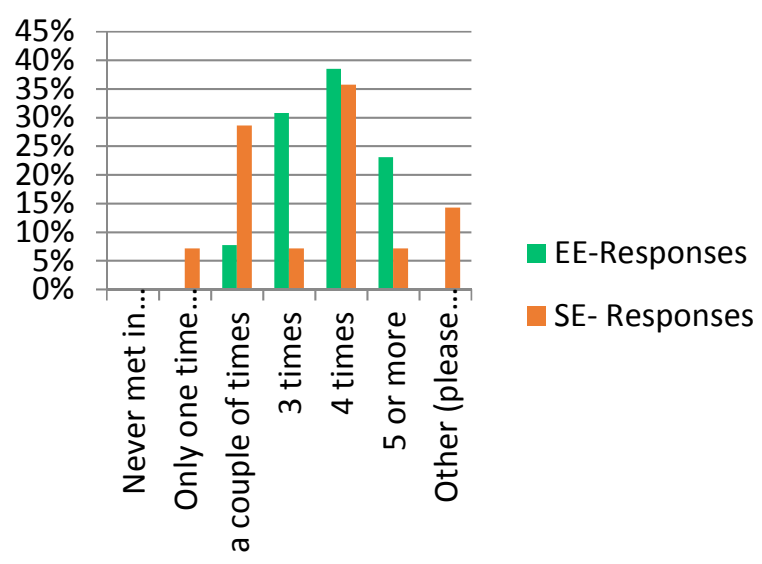

Were your team timeline and SE team timeline synced?

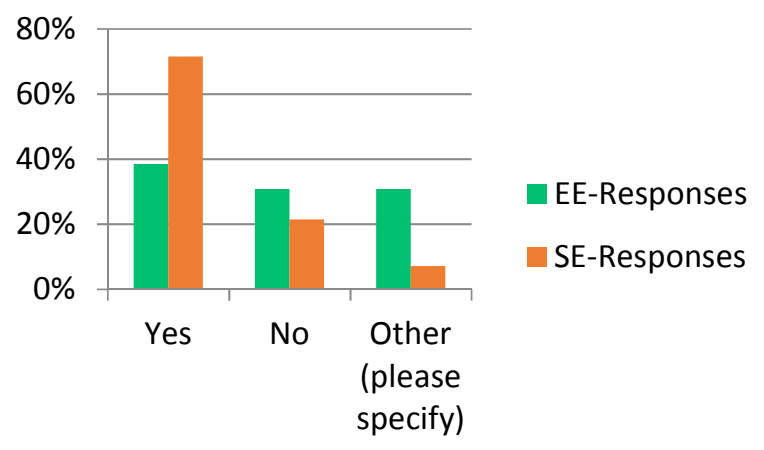


Are you satisfied or dissatisfied with the overall quality of the work performed by SE/EE team?

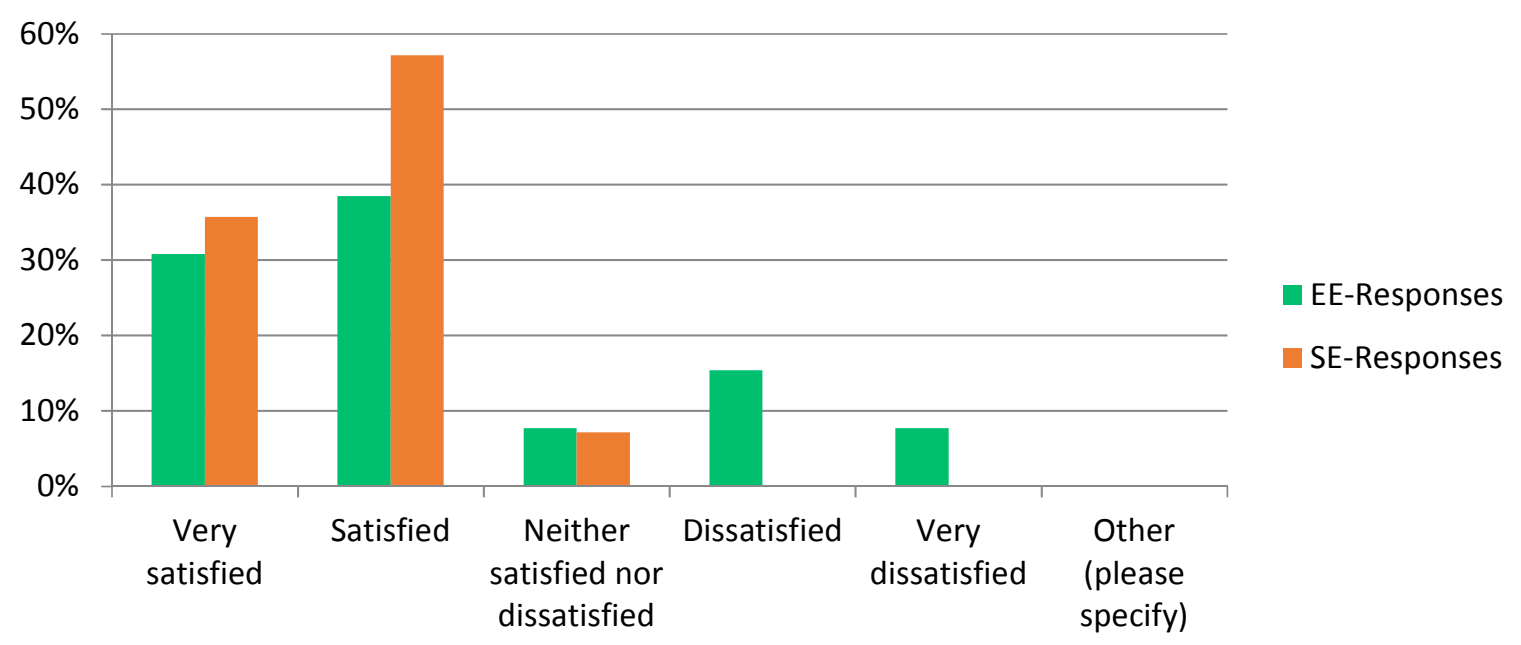

Figure 3. The percentage of responnders to the Question "Are you satisfied or dissatisfied with the overall quality of the work performed by SE/EE team?"

How did you develop the plan with SE team?

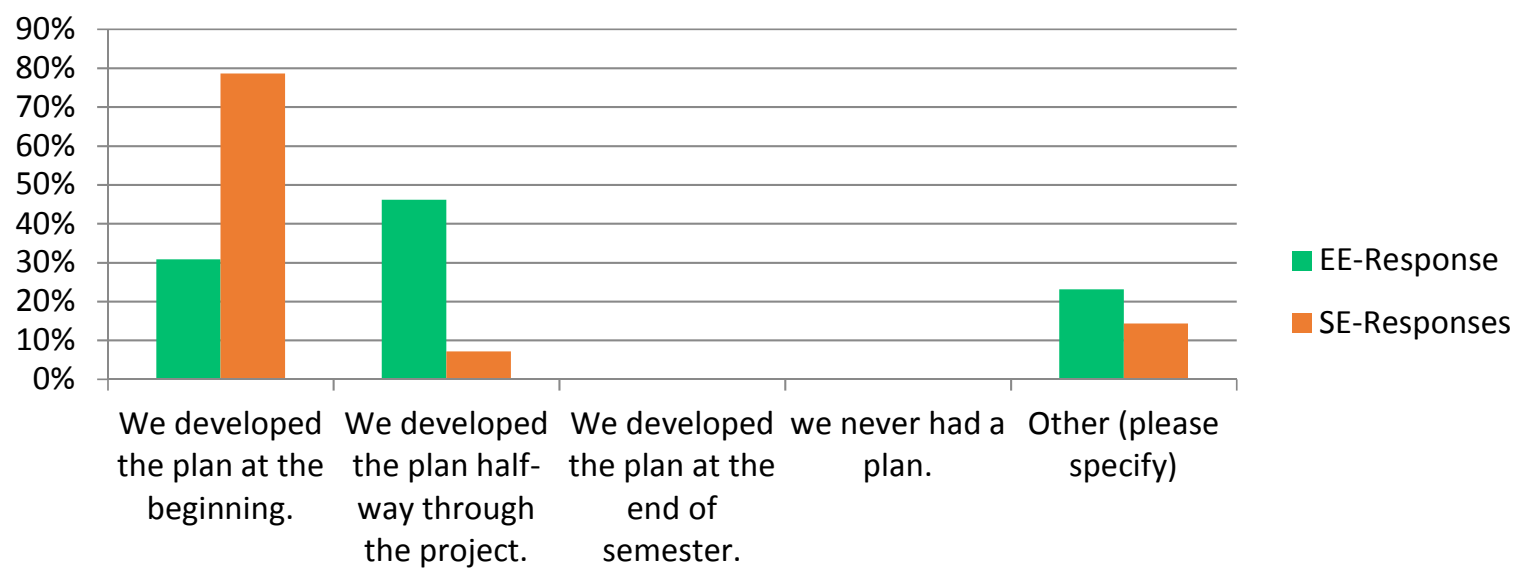

Figure 4. The percentage of responders to the question "How did you develop the plan with SE team?" 